\title{
Paediatrics: tackling the common problems
}

\author{
A series looking at everyday practice in the light of the evidence
}

$\mathrm{T}$ he health of the first two of Shakespeare's seven ages of man - "the infant, mewling and puking" and "the whining school-boy"1 - is the domain of paediatricians, paediatric surgeons and general practitioners. Paediatrics is a relatively new discipline. The first Professor of Paediatrics in Australia, Sir Lorimer Dods, was appointed to the University of Sydney in 1949, but it was not until the late 1960s that a common written examination for paediatrics and adult medicine was abandoned, and the medical world formally recognised that children are not just little adults when it comes to health and disease. Today, paediatrics is a vibrant discipline encompassing the whole gamut of medical subspecialties, plus some exclusive to childhood, such as neonatology and child development.

The differences between the disciplines of paediatrics and internal medicine are far greater than those embodied in the observation that children are not just scaled-down adults. Most of the children admitted for acute care to Australian paediatric hospitals are still cared for by general paediatricians, while it is a long time since generalists fulfilled this role for adults in tertiary hospitals. Subspecialty practice in paediatrics is also different: children's health problems differ from those of adults, and subspecialty practice is almost exclusively hospital or university based.

In this issue of the Journal, we begin a Practice Essentials series on paediatrics that will focus on the common problems confronting paediatricians and, by extension, general practitioners. We could have chosen to cover the recent technological and pharmacological advances in paediatrics (of which there are many), but most, although not all, of these have their origin in adult medicine, partly because of a correct emphasis on the ethical considerations of experimentation in children, and partly because of the commercial considerations of the pharmaceutical and biotechnology industries.

The problems we have chosen to feature are low technology and predominantly concern development and neurocognition. In 2002, 62 general paediatricians in Victoria were asked which of the clinical conditions they dealt with were the most difficult. ${ }^{2}$ The responses were illuminating: $26 \%$ listed conduct disorder, $24 \%$ family dysfunction, $18 \%$ eating disorder, $15 \%$ autism spectrum disorder, 13\% children at risk, and 13\% attention deficit disorder. A previous study looked at how six paediatricians spent their time during 12 months of community paediatric consultation: ${ }^{3} 3875$ of 14711 (26.3\%) consultations were for attention deficit hyperactivity disorder and learning problems, and 1917 (13.0\%) were for intellectual disability. The most common medical condition was asthma (1470 consultations; 10\%), followed by constipation and/or encopresis (966; $6.6 \%$ ), and urinary tract infection and enuresis combined (815; $5.6 \%)$.

In planning this series, potential topics were focused through the "camera obscura" of a group of general practitioners. The topics chosen reflect very closely the experience of the Victorian general paediatricians, and include developmental and learning

\section{Topics covered by the Paediatrics series}

- Problem crying in infancy

- Acute infectious diarrhoea and dehydration

- Prevention and treatment of obesity

- Bedwetting, constipation and toileting issues

- Autism and language disorders

- Atopic disease

- Obstructive and other sleep disorders

- Developmental, learning and behavioural problems

- Minor trauma

- Care of the child in Australian society

problems, autism and language disorders, constipation, bedwetting, and the most common eating disorder — obesity. A complete list of the topics is given in Box 1 .

Problematic childhood behaviours often make a major contribution to family dysfunction, and problem crying in infancy and sleep disturbance can test the resilience of families and marriages. These disorders often do not have a significant underlying physical problem, but may be symptomatic of difficult family relationships.

Paediatricians have to keep in mind that their patients grow up and stewardship will pass into other hands. Equally, we cannot practise in isolation - we need to be aware of the childhood lifestyle disorders that are determinants of adult disease. The child is indeed "father of the man". ${ }^{4}$ The pandemic of obesity facing Australia and other developed countries has its genesis in childhood. Realistic management of this problem must involve strategies to decrease sedentary behaviour, particu-

\section{Designation of levels of evidence of the National Health and Medical Research Council ${ }^{6}$}

Level I: Evidence obtained from a systematic review of all relevant randomised controlled trials.

Level II: Evidence obtained from at least one properly designed randomised controlled trial.

Level III-1: Evidence obtained from well-designed pseudorandomised controlled trials (alternate allocation or some other method).

Level III-2: Evidence obtained from comparative studies (including systematic reviews of such studies) with concurrent controls and allocation not randomised, cohort studies, case-control studies, or interrupted time series with a control group.

Level III-3: Evidence obtained from comparative studies with historical control, two or more single-arm studies, or interrupted time series without a parallel control group.

Level IV: Evidence obtained from case series, either post-test or pretest/post-test. 


\section{MJA PRACTICE ESSENTIALS - PAEDIATRICS}

larly television and computer viewing in childhood, and also to promote physical activity and appropriate dietary intake. Another determinant of lifestyle disease in adulthood is upperairway obstruction. Children who snore have been shown to have a neurocognitive disadvantage compared with their peers of the same age and socioeconomic group.

The series concludes with an article on the care of children in Australian society. This reminds us about the social determinants of health, which are fundamental to our understanding of child growth and development. ${ }^{5}$ Academic paediatricians teach medical students to be a conduit for entitlements for their patients. Paediatricians need to become more involved in policymaking and advocacy. Parents of children with autism, as well as those with children with chronic disability, are beginning to demand this and they should be heeded.

Finally, in addressing each of these important topics, the authors have sought to apply the best evidence available. Each article includes some evidence-based practice tips, with the level of evidence graded according to the National Health and Medical Research Council's system for assessing evidence (Box 2).

We hope you will enjoy this series and that it will provoke debate and discussion.
Richard T L Couper Senior Paediatric Gastroenterologist, Women's and Children's Hospital University of Adelaide, Adelaide, SA

Richard L Henry Senior Associate Dean, Faculty of Medicine University of New South Wales, Sydney, NSW

Michael South Director, Department of General Paediatrics, Paediatric Intensivist, Royal Children's Hospital, University of Melbourne, Melbourne, VIC

1 Craig WJ, editor. The Oxford Shakespeare. The complete works of Shakespeare. (As you like it, Act II, Scene vii, The seven ages of man). London: Oxford University Press, 1914; New York: Bartleby.com. 2000.

2 Cooper CR, Hewson PH. The most difficult clinical situations: a survey of Victorian General Paediatricians. J Pediatr Child Health 2002; 38: 455-458.

3 Hewson PH, Anderson PK, Dinning AH, et al. A 12 month profile of community paediatric consultations in the Barwon region. J Paediatr Child Health 1999; 35: $16-22$.

4 Quiller-Couch AT, editor. The Oxford book of English verse William Wordsworth, 532. The rainbow). Oxford: Clarendon, 1919; Bartleby.com, 1999.

5 Keating DB, Hertzman C, editors. Developmental health and the wealth of nations. New York: Guildford Press, 1999.

6 National Health and Medical Research Council. How to use the evidence: assessment and application of scientific evidence. Handbook series on preparing clinical practice guidelines. Table 1.3: Designation of levels of evidence. Canberra: NHMRC, February 2000: 8. Available at: www.health.gov.au/nhmrc/ publications/pdf/cp69.pdf (accessed Sep 2004). 